\title{
Investigation of increased corrosion wear of heat exchange equipment pipes
}

\author{
Oleg Kiselev*, Dmitry Polikarpov, and Anna Demidova \\ JSC VNIKTINHO, Laboratory of analytical chemistry and corrosion, 400087 Volgograd, Russia.
}

\begin{abstract}
The article discusses the stages of research to determine the possible causes of increased corrosion wear of tube bundles of heat exchangers. The most typical types of damage to heat exchanger pipes are shown, depending on the operating conditions. Recommendations aimed at reducing the corrosion wear of pipe bundles for typical operating conditions at oil refining enterprises.
\end{abstract}

\section{Introduction}

In modern oil refineries, improving the reliability of technological equipment operation is an important and urgent task from the point of view of corrosion. Its solution allows to increase the financial efficiency of production by reducing the downtime of technological installations, the cost of eliminating accidents and incidents, equipment repairs, and also allows to increase the safety of production. A high percentage of failure due to corrosion wear is observed for heat exchange equipment, and in particular pipe bundles, which leads to a large number of operating costs of petrochemical enterprises [1].

Thus, the aim of the work is to study the possible causes of increased corrosive wear of tube bundles of heat exchangers at oil refineries and to develop recommendations for its reduction.

\section{Materials and method of research}

The research was carried out on cuttings from damaged heat exchangers obtained from technological installations of oil refineries (CDU/VDU, catalytic reforming, hydrotreating of diesel fuel, catalytic cracking). The presented heat exchanger tubes are made of the following materials: carbon steel, $08 \mathrm{Cr} 18 \mathrm{Ni1} 10 \mathrm{Ti}$, 10Cr17Ni13Mo2Ti, $15 \mathrm{Cr} 5 \mathrm{Mo}$. The work included the following stages:

- study of reference documentation for the object, visual and measuring control, determination of sampling sites;

- microscopic analysis of morphology and chemical analysis of corrosion deposits;

- determination of the influence of operating conditions on the damage of the studied area;

- analysis of research results to determine the cause of corrosive wear;

- development of recommendations for improving reliability.

\subsection{Morphological features of deposits}

The deposits selected from the inner and outer surfaces of the tubes were checked for their relation to the external magnetic field and morphological features: color and structure. If necessary, a microscope was used.

\subsection{Chemical analysis of corrosion deposits}

For deposits collected from the inner surface of the tubes (from the recycled water side), analysis was performed in the initial sample, water extract, and calcined residue. Prior to chemical analysis, the deposits were ground into a fine powder and divided into three samples:

1) For water extraction of soluble substances, distilled water of single distillation with $\mathrm{pH}=5.4$ was used. In the extract, the $\mathrm{pH}$ value, the content of chlorides (argentometrically), sulfates (in the form of barium sulfate nephelometrically), and iron in a soluble form (using the photocolorimetric method with sulfosalicylic acid) were controlled.

2) For the sample in the initial state, the presence of sulfide sulfur was controlled by darkening the filter moistened with lead acetic acid, for which the sample was wetted with water, treated with hydrochloric acid, and heated to extract hydrogen sulfide from the sample. The total sulfur content was determined after preliminary oxidation of sulfur compounds to sulfate ions by bromine and nitric acid in the form of barium sulfate using a photocolorimeter nephelometrically. The iron content was calculated taking into account the percentage of the residue obtained during calcination, based on the iron content in the calcined residue.

3) To analyze the calcined residue, the sample was calcined at a temperature of $800^{\circ} \mathrm{C}$ for 1 hour with air access, converting all metal compounds, including iron, into oxides. The residue after calcination was determined gravimetrically. The total iron in the calcined sample was determined from an acid extract with sulfosalicylic acid photocolorimetrically. Calcium was determined by

\footnotetext{
Corresponding author: kisssell@yandex.ru
} 
titration with Trilon B from an acid extract after precipitation with an ammonia solution of iron hydroxide and subsequent filtration.

For each quantitative analysis, samples were sampled with an accuracy of 0.0001 grams.

\section{Results and discussion}

Typical cases of damaged tubes of heat exchangers obtained in 2019-2020 from various installations of oil refineries are considered below.

1) The object of the study was a fragment of the beam tube of the refrigerator-condenser. The Refrigerator-condenser is located in the helmet line of the stabilization column of the catalytic reforming unit and designed for condensation of vapors of light hydrocarbons. Material design of pipes - carbon steel.

Figure 1 shows the nature of deposits and the type of corrosion damage on the inner surface of the pipe. The inner part of the pipe is covered with gray deposits, a dense layered structure, on the surface of which there is a thin precipitation of light-brown iron oxides, characteristic of such a compound as goethite $\alpha-\mathrm{FeOOH}$. On the surface of the metal, there is a continuous nonuniform corrosion with signs of the origin of ulcers of a rounded shape, with a diameter of up to $3 \mathrm{~mm}$ and a depth of about $0.5 \mathrm{~mm}$. There is an intense wear of the surface.

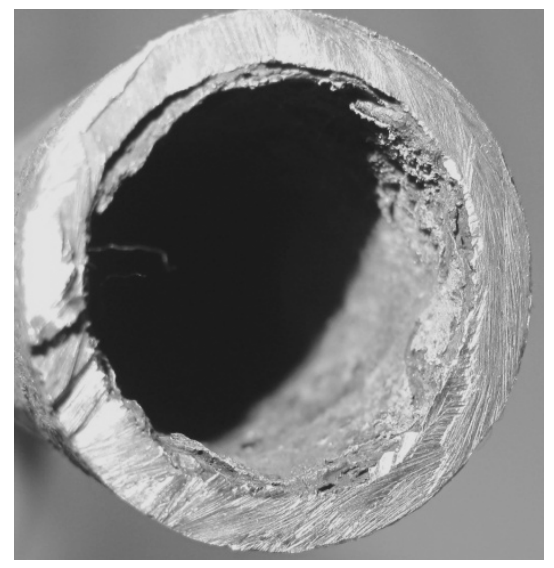

Fig. 1. The nature of deposits and the type of corrosion damage on the inner part of the pipe surface.

Chemical analysis of the deposits showed the content of soluble iron sulfates, which are usually formed as a result of chemical decomposition of water-insoluble iron sulfides under the action of moisture and air oxygen during equipment downtime. Thus, it follows that the cause of failure of the pipes of the tube bundle of the condenser-refrigerator is the tendency of working environments to cause ulcerative corrosion of carbon steel in the inter-tube space.

It should be noted that for the operating conditions of the refrigerator, it is recommended, according to RTM 26-02-42-78 "Methods of protection against corrosion and the choice of materials for the main elements and components of devices for catalytic reforming installations" [2], the following material design, provided that such compounds as ammonia and hydrogen chloride are not present in the medium: a brass tube bundle.

2) The object of research is two fragments of tubes from the horizontal tube bundle of the shell-and-tube heat exchanger. Processing medium of the pipe space water, operating temperature $-45^{\circ} \mathrm{C}$, material of construction - $08 \mathrm{Cr} 18 \mathrm{Ni} 10 \mathrm{Ti}$; inter-pipe space-gasoline, operating temperature - $100^{\circ} \mathrm{C}$, material 08Cr18Ni10Ti.

The outer surface of the metal samples is covered with a thin layer of black deposits, probably characteristic of iron compounds (figure 2). When examining ulcerative lesions in a 12-fold increase from the side of gasoline and water, it can be argued that the origin of defects occurs from the side of the medium flowing in the inter-tube space-gasoline.

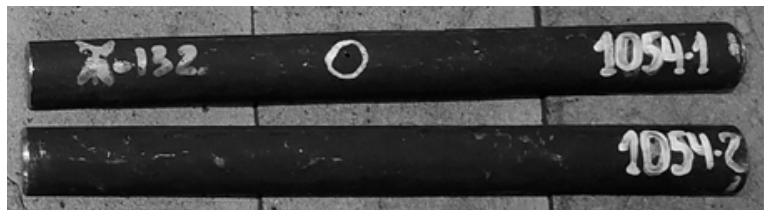

Fig. 2. Sample tubes - the outer side.

The gasoline vapor condensation and cooling line uses imidosaline corrosion inhibitors, which create a protective film on the walls of the equipment, reducing the likelihood of contact of the base metal with aggressive components of the medium - sulfides, chlorides and condensed moisture. From the experience of operation and testing of such inhibitors, it is known that if the content of chlorine-ion in the aqueous phase is more than $40 \mathrm{mg} / \mathrm{dm}^{3}$, it is possible to destroy the protective film. One-time measurements of chloride content in drainage water according to the plant data for the period 12.02.19-12.03.19 they ranged from 4.6 to $106.2 \mathrm{mg} / \mathrm{dm}^{3}$, i.e., under operating conditions, there is a probability for periodic destruction of the protective film of the corrosion inhibitor and the creation of conditions for local corrosion. Increasing the dosage of these inhibitors will not protect from the effects of chlorides. Therefore, as recommendations, it is proposed to consider the option of choosing an inhibitor that provides protection from the effects of chlorides in wide ranges of concentrations that cover the maximum detectable amount of them according to the analysis of drainage water from the reflux tank. To analyze the drainage of water on the chloride content at least once a day. Organize the possibility of entering both currently used inhibitors and designed to protect against chlorides. When the concentration of chlorides in drainage water exceeds $40 \mathrm{mg} / \mathrm{dm}^{3}$, enter an inhibitor to provide protection against chlorides. After receiving analytical data on reducing the concentration of chlorides to less than $40 \mathrm{mg} / \mathrm{dm}^{3}$, switch the supply of the inhibitor to the currently used one. In addition, it is possible to use pipes made of more corrosion-resisting steel in these operating conditions - 08Cr17Ni15Mo3Ti, 08Cr21Ni6Mo2Ti.

3) The object of research is the heat exchange tube of a refrigerator units of primary oil refining CDU/VDU. The working environment of the pipe space - recycled 
water, operating temperature $-27^{\circ} \mathrm{C}$, material version 10Cr17Ni13Mo2Ti; inter-pipe space - hydrocarbons, operating temperature - $90^{\circ} \mathrm{C}$, material version 10Cr17Ni13Mo2Ti.

After cleaning the tube, it was found that the nature of the corrosion effect, both from recycled water and hydrocarbons, has an uneven character with elements of local corrosion damage in the form of pitting (figure 3), destroying the surface oxide film. The difference is in the amount of local damage on the tube surfaces. The density distribution of pitting on the inner surface of the tube is $2-3$ pieces per $50 \mathrm{~mm}$ of tube length.

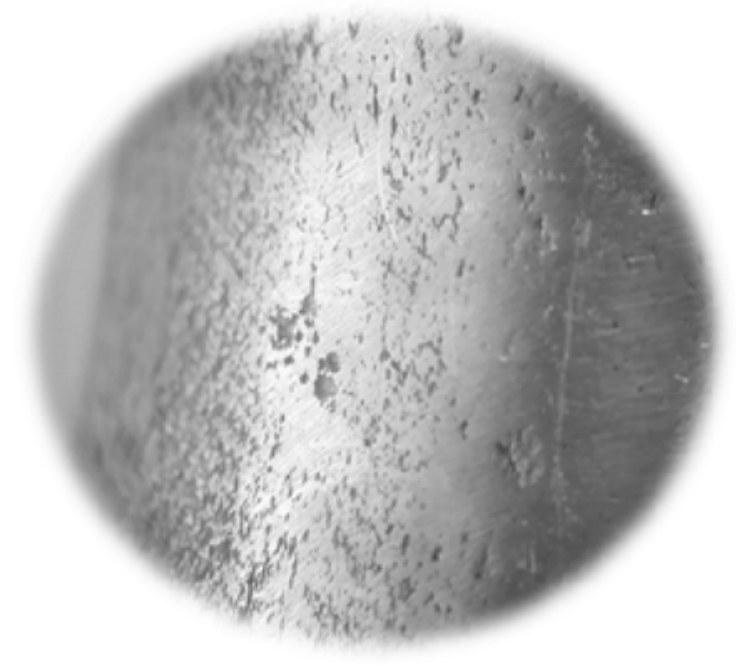

Fig. 3. General view of the tube surface after Stripping of deposits from the hydrocarbon side.

The occurrence of pitting is associated with a violation of the passive state on certain areas of the metal surface as a result of the action of chlorides. At these sites, accelerated destruction of oxide films occurs, which causes local sensitization. Violation of the passive state in certain areas leads to an increase in the rate of corrosion with the further development of pitting and in the case of external stresses can provoke the development of chloride corrosion cracking.

4) The object of research is the tubes of the double shell-and-tube heat exchanger of the complex installation CDU/VDU. Working environment of the pipe space tar, operating temperature $-300^{\circ} \mathrm{C}$, material version carbon steel; inter-pipe space -desalinated oil, operating temperature $-220^{\circ} \mathrm{C}$, material version - carbon steel.

After cleaning, it was found that the nature of corrosion from the tar on the entire inner surface of the tubes is uneven with a tendency to form ulcers, with different shapes and penetration depth up to $0.2-0.3 \mathrm{~mm}$. Figure 4 shows that the deposits are particles of various sizes of dark brown and black color, which is typical for a mixture of iron sulfides and oxides of the goethite $\mathrm{FeO}(\mathrm{OH})$ type.

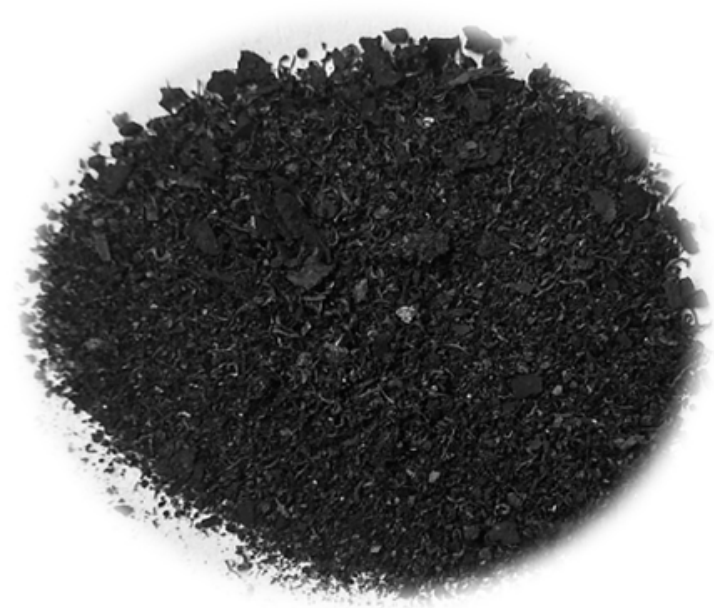

Fig. 4. The appearance of the sediments from the tar.

Based on morphological, x-ray fluorescence and chemical analysis of the composition of deposits on tar and desalinated oil, it was found that the main damaging factor is hydrogen sulfide corrosion, and for tubes from the contact with tar, it has the character of hightemperature (HTSC), which causes more significant corrosion damage compared to the impact on the metal from desalinated oil. HTSC iron proceeds by the reaction $\mathrm{Fe}+\mathrm{H}_{2} \mathrm{~S}=\mathrm{FeS}+\mathrm{H}_{2}$. In this case, the protective properties of the metal will have the resulting sulfide film. But at temperatures from 260 to $650^{\circ} \mathrm{C}, \mathrm{FeS}$ films gradually turn into porous layers that do not represent a barrier to hydrogen sulfide. As a result, the controlling role of the diffusion of iron ions through the sulfide layer finally disappears, and the corrosion kinetics begins to be determined by the rate of reaction of iron with hydrogen sulfide with the formation of ulcerative lesions characteristic of the studied metal cuts. The difference in the nature of ulcerative lesions on the inner and outer surfaces of the tubes is due to different temperatures in the tube and inter-tube space of the heat exchanger. The higher the temperature, the greater the corrosion wear of the surface, which is characteristic of the studied tubes. The service life of the device from the moment of its commissioning is 22 years. There is no data on replacing the tube bundle in the passports. The long service life of the device, combined with minor corrosion damage, indicates a fairly high corrosion resistance of carbon steel tubes in the operating conditions of the heat exchanger.

5) The object of research is tubes with through damages cut from the tube bundle of the heat exchanger for heating desalinated oil with diesel fuel. The heat exchanger is operated on the CDU/VDU installation. The working environment of the pipe space - desalinated oil, operating temperature $-150^{\circ} \mathrm{C}$, material version $15 \mathrm{Cr} 5 \mathrm{Mo}$; inter-tube space - diesel fuel, operating temperature $-300^{\circ} \mathrm{C}$, material version $-15 \mathrm{Cr} 5 \mathrm{Mo}$.

Visual inspection revealed single through holes on the tube fragments (figure 5). The defects have an oval shape, and are elongated along the generative. 


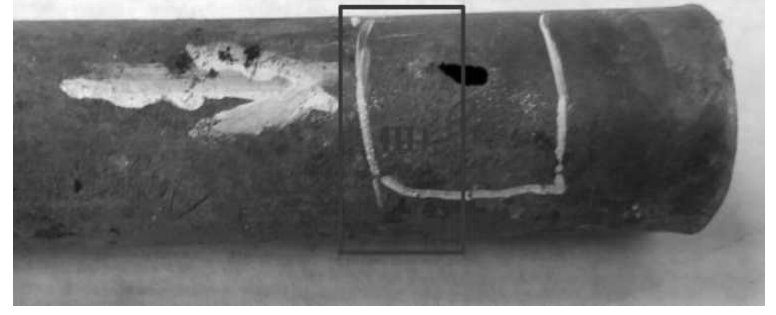

Fig. 5. The nature of the corrosion damage to the tube.

The cause of through damage to the tubes of the heat exchanger in the adjacent zone to the pipe grid is the formation of specific deposits from the desalinated oil, under which ulcerative corrosion develops. This condition of the surface causes the formation of differential aeration pairs, which stimulates increased corrosion in certain places, in our case under porous deposits near the grid. In areas far from the pipe grid, the corrosion is uniform and tube wear is not significant.

The type of tube surface corrosion from desalinated oil is hydrogen sulfide. In this case, a significant amount of iron sulfides with pyrophoric properties is formed. From the diesel fuel side, the corrosion of the tubes is uniform with signs of local pitting that breaks through the protective oxide film. Recommended technology departments to assess the possibility of entering the plant oil with high content of organochlorine compounds and possibly other substances, which caused the accumulation in the sediments of substances with a pungent odor. Perhaps the sharp smell is associated with the use of new chemical agents in oil fields or oil treatment plants with unexplored behavior in the area of elevated temperatures, which identification is possible at the stage of analysis of the raw material - crude oil.

6) The object of research is the heat exchange tubes of the shell-and-tube refrigerator. The working environment of the pipe space - recycled water, operating temperature $-25^{\circ} \mathrm{C}$, material version - carbon steel; inter-pipe space - petroleum products, operating temperature $-45^{\circ} \mathrm{C}$, material version - carbon steel.

Visual inspection of the tubes of the refrigerator showed that there are through damages and originate from the recycled water.

The most likely reason for the formation of gaps is the low flow rate of the medium from the recycled water, which contributes to the formation of precipitation on the lower forming tube, as indicated by the increased thickness of deposits in this zone. This assumption is confirmed by the results of the analysis of deposits on the content of calcium cations in the calcined sample, which were found in small quantities and indicate that the deposits are not falling out and compacting hardness salts, but have a sedimentary character. It is known that moisture accumulates under the sediment, which initiates the flow of corrosion processes by an electrochemical mechanism, leading to a decrease in $\mathrm{pH}$ in conditions of difficult access of oxygen to the metal surface. Actively dissolving metal under deposits subsequently leads to local corrosion damage.

To avoid such a corrosive effect, it is recommended to: consider increasing the flow rate (at least $1 \mathrm{~m} / \mathrm{s}$ ) in the tubes to reduce the possibility of precipitation along their lower generators [3]; during major repairs, perform a hydro-jet cleaning of deposits in accordance with Standard of organization 00151526-001-2016 [4]. This operation can be performed directly on the site of operation of heat exchangers using a mobile kit for cleaning pipe bundles. The method of hydro-jet cleaning is based on the effect of a jet of liquid - water with high kinetic energy on the processed material.

7) The object of research was the metal tube of the heat exchanger. During hydraulic tests, a missing heat exchange tube was detected, and further inspection revealed ulcerative corrosion (figure 6). Working environment of the pipe space - oil, operating temperature $-160^{\circ} \mathrm{C}$, material version - steel $15 \mathrm{Cr} 5 \mathrm{Mo}$; inter-pipe space - diesel fuel, operating temperature $200^{\circ} \mathrm{C}$, material version - steel $15 \mathrm{Cr} 5 \mathrm{Mo}$.

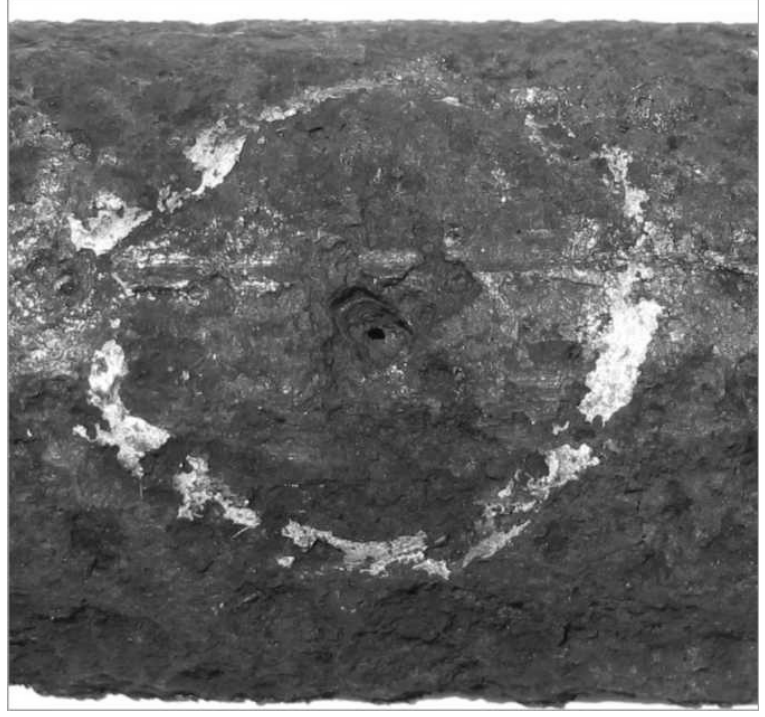

Fig. 6. The nature of the corrosion damage to the tube.

Corrosion damage to the tubes from diesel fuel is specifity, not previously observed in such working environments of CDU installations. Ulcerative corrosion on the surface of the fragments of the tube is probably associated with the presence of chloride compounds in the working environment, which are both products of hydrolysis of calcium and magnesium salts that remain in the oil during the established and stable operation of the CDU unit in small quantities, and organochlorine thermostable compounds. This is evidenced by the nature of the detected defects - the presence of a dense layer of deposits, ulcerative through-corrosion, the development of local corrosion damage not under the layer of deposits.

It is recommended that the plant's technological services analyze the possibility of receiving oil with an increased content of organochlorine compounds that contribute to the formation of hydrogen chloride, with further development of recommendations for reducing this corrosive component in the medium (multiple dilution with raw materials with a low content of organochlorine compounds). 
8) The object of research was the metal tube of the refrigerator. Working environment of the pipe spacewater, operating temperature $-25^{\circ} \mathrm{C}$, material version carbon steel; inter-pipe space - gas product mixture, operating temperature $-50^{\circ} \mathrm{C}$, material version - carbon steel. Figure 7 shows that the inner surface of the tubes is subject to single ulcerative lesions. Through ulcerative injuries were not detected, their appearance in other places of the pipes from the pipe bundle of the refrigerator is not excluded.

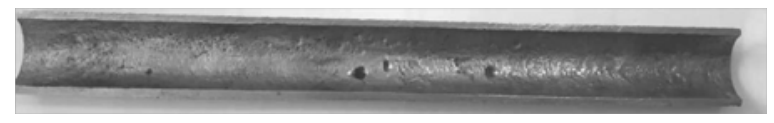

Fig. 7. The nature of damage to the inner surface of the tube after Stripping from deposits.

Specific damage to the tube from the recycled water in the form of local convex inhomogeneities (swellings) of red color, under the upper layer of which there are hollow depressions in the form of ulcers with deposits of black color such as iron sulfides, can be caused by the flow of microbiological corrosion. The optimal conditions for the occurrence of microbiological corrosion caused by sulfate-reducing bacteria are: presence of sulfates, thiosulfates, and sulfates in recycled water; $\mathrm{pH}$ value within 6-7,5; temperature $25-30{ }^{\circ} \mathrm{C}$. These conditions are typical for the recycled water of the refrigerator (chemical analysis of deposits confirmed the presence of sulfates, as well as $\mathrm{pH}=6,61$ ). Since sulfatereducing bacteria are anaerobes, the mechanism of action of bacteria on the metal surface is that under the deposits (blisters) formed zones depleted of oxygen, which is the main corrosive agent in water. It follows that zones with different aeration are formed on the surface of the tubes, i.e. pairs of differential aeration, in which zones depleted of oxygen corrode more intensively and cause ulcerative corrosion.

It is necessary to check the assumption of microbiological corrosion of the pipes from the recycled water by selecting the necessary samples, obtaining crops, determining the types, classes and genera of sulfate-reducing bacteria with further development of recommendations for chemical treatment of recycled water with bactericides and/or necessary reagents to avoid ulcerative damage to the refrigerator pipes.

\section{Conclusions}

Thus, the research results presented above have shown that the appearance and development of pipe bundles corrosion damage depends on the temperature, flow rate of the working medium, the content of corrosive components in it, and the material design of the pipes.

For primary oil processing plants, the most characteristic is the corrosion wear of pipe bundles in the form of ulcer and pitting corrosion under the action of chlorides and moisture, which can be contained in recycled water, gasoline fraction, diesel fuel, as well as high-temperature hydrogen sulfide corrosion in environments with a high concentration of sulfur- containing compounds. Deep oil refining plants are also characterized by ulcerative damage and corrosion cracking, which are caused by chlorine-containing compounds and moisture, in addition, there have been cases of microbiological corrosion under the action of sulfate-reducing bacteria for the media of recycled water and petroleum products.

These recommendations aimed at reducing the corrosion wear of pipe bundles for typical operating conditions at the enterprises of the oil refining complex and will reduce the risk of production, as well as optimize operating costs.

\section{References}

1. Bolotova Y.V., Ruchkinova O.I., Corrosion of heat exchange equipment of petrochemical plants (Herald of the Perm national research Polytechnic University, 4, 2015)

2. PTM 26-02-42-78 «Methods of corrosion protection and selection of materials for the main elements and components of devices and catalytic reforming installations»»

3. PTM 26-02-39-84 «Methods of corrosion protection and selection of materials for the main equipment and pipelines of oil treatment and primary processing plants (CDU/VDU)»

4. Standard of organization 00151526-001-2016, Shell-and-tube heat exchangers. General technical conditions for repairs 